ORIGINAL RESEARCH - QUALITATIVE

\title{
Developing competence and confidence in midwifery-focus groups with Swedish midwives
}

\author{
Lena Bäck ${ }^{\mathrm{a}, *}$, Ingegerd Hildingsson ${ }^{\mathrm{a}, \mathrm{b}}$, Carina Sjöqvist ${ }^{\mathrm{c}}$, Annika Karlström ${ }^{\mathrm{a}}$ \\ a Department of Nursing, Mid Sweden University, Sweden \\ ${ }^{\mathrm{b}}$ Department of Women's and Children's Health, Uppsala University, Sweden \\ ${ }^{\mathrm{c}}$ The County Hospital of Östersund, Maternity Unit, Sweden
}

\section{A R T I C L E I N F O}

\section{Article history:}

Received 18 November 2015

Received in revised form 2 August 2016

Accepted 5 August 2016

\section{Keywords:}

Competence

Confidence

Midwifery

Knowledge

Learning

\begin{abstract}
A B S T R A C T
Background: Midwives have a significant impact on the clinical outcome and the birthing experience of women. However, there has been a lack of research focusing specifically on clinical midwives' learning and development of professional competence.

Aim: The objective of the study was to describe how midwives reflect on learning and the development of professional competence and confidence.

Methods: A qualitative study based on focus groups with midwives employed in maternity services.

Findings: Four categories describe the results: (1) Feelings of professional safety evolve over time; (2) Personal qualities affect professional development; (3) Methods for expanding knowledge and competence; and (4) Competence as developing and demanding. The meaning of competence is to feel safe and secure in their professional role. There was a link between the amount of hands-on intrapartum experience and increasing confidence that is, assisting many births made midwives feel confident. Internal rotation was disliked because the midwives felt they had less time to deepen their knowledge and develop competence in a particular field. The midwives felt they were not seen as individuals, and this system made them feel split between different assignments.

Discussion: External factors that contribute to the development of knowledge and competence include the ability to practise hands-on skills in an organisation that is supportive and non-threatening. Internal factors include confidence, self-efficacy, and a curiosity for learning.

Conclusions: Midwives working within an organisation should be supported to develop their professional role in order to become knowledgeable, competent and confident.
\end{abstract}

( 2016 Australian College of Midwives. Published by Elsevier Ltd. All rights reserved.
Statement of Significance:

\section{Issue}

There is a lack of research focusing specifically on clinical midwives, their learning and striving to gain professional competence.

\section{What is already known}

Midwifery competence is related to confidence, and it is a lifelong learning process. Midwives need to be strong and confident to meet the expectations of their position.

\footnotetext{
* Corresponding author at: Department of Nursing, Mid Sweden University, Kunskapens väg 8, 83140 Östersund, Sweden.

E-mail addresses: lena.back@miun.se (L. Bäck), ingegerd.hildingsson@miun.se (I. Hildingsson), carina.sjoqvist@regionjh.se (C. Sjöqvist),

annika.karlstrom@miun.se (A. Karlström).
}

\section{What this paper adds}

Insight into how clinical midwives reflect on competence and how to develop confidence.

\section{Introduction}

Midwives have an important and significant impact on the medical outcome and the birthing experience of women. ${ }^{1-3}$ The midwifery profession requires knowledge, competence, confidence and skills, and the competent and confident midwife can make the difference between life and death. ${ }^{4}$ The profession of midwifery is based on the standards of the International Confederation of Midwives (ICM). ${ }^{5}$ The ICM is a federation of midwifery associations representing countries across the globe. ICM has developed a 
description of competences that are required for becoming a midwife, and a definition of the scope of practice for midwives.

Midwifery training and education varies across the globe and the content, length and level of curriculum differ among countries. ${ }^{5}$ The field of midwifery in the Swedish context has gradually broadened and extends to professional work with and for woman's sexual and reproductive health from a life cycle perspective. ${ }^{6,7}$ A growing body of research has resulted in new professional domains, such as counselling and support to women with childbirth fear, and those who need help with contraception and ultrasound scans. ${ }^{8}$ Professional competence in several areas is also required for midwives working in small units with internal rotation between labour wards, postnatal and gynaecological wards.

The concepts of competence and confidence are not synonymous, but may be linked. Confidence is defined as "a feeling of selfassurance arising from an appreciation of one's own abilities or qualities". Competence is defined as "the ability to do something successfully or efficiently". 9 There are three influencing attributes to confidence: dispositional (attitudes, personal traits and motivation); situational (depends on personal time and recourses); and institutional (structure and pedagogy of educational programmes). ${ }^{10-13}$ Increased levels of confidence may not be in proportion to increased competence, but decreased confidence could be linked to a reduction in skilled performance. ${ }^{14}$

Midwives have to incorporate theoretical knowledge, practical skills and also use their personal attributes, like empathy and intuition. ${ }^{15}$ Further, midwives have to interact with women in a personal and professional way. On the personal level there is a need for self-efficacy. Self-efficacy is described, as "the belief in ones capabilities to organise and execute the courses of action required managing prospective situations". ${ }^{16}$ Berggren has described midwives' attitudes relating to the development of professional competence; competence was said to grow with the everyday practice of hands-on skills. ${ }^{17}$ Norman and Hyland point out that development of professional competence depends on circumstances related to the workplace and confidence can be increased or diminished. They meant that confidence can be linked to a feeling of personal security, and may be increased when a person feels secure and receives positive feedback. ${ }^{10}$ In a midwifery context, organisational factors such as the influence of colleagues, perceived autonomy and a sense of familiarity can contribute to enhancing confidence. It is clearly important for midwives to improve their confidence and the organisation should engage in considerable efforts to do so. ${ }^{18}$

The concepts of knowledge and competence are complex and include hands-on skills training, but also personal factors, such as self-efficacy, confidence and a capacity for critical thinking. Strong and confident midwives are needed in the profession. Midwives who feel well prepared to meet a pregnant woman's needs and have the opportunity to practice within the full scope of their role to become autonomous practitioners. ${ }^{12,19,20}$

Research clearly demonstrates the importance of being a competent midwife with the confidence to practice, including the ability to make critical decisions in urgent situations; therefore, professional autonomy is crucial. However, there is a lack of research that focuses on clinical midwives and the processes followed to enhance competence. This study intends to explore how midwives reflect on learning and the development of professional competence and confidence in a working context.

\section{Methods}

\subsection{Design}

A qualitative design was used; the intention was to understand the midwives' experiences of developing professional competence.
Focus groups were used to collect the data. Focus groups offer a major advantage in that they are efficient and the researchers can obtain the viewpoint of many people in a short time. ${ }^{21}$

\subsection{Setting and sample}

The study used a purposive sample of midwives from four county hospitals in central Sweden. The hospitals where the focus groups took place varied in size from 299 to 1972 births per year.

The homogenous and purposive sampling was used with the intention to deepen the understanding of how midwives reflect on learning and the concepts of knowledge and competence. A letter was sent to four department managers asking for approval to conduct focus groups. The inclusion criteria were midwives working in labour wards who were interested to share their experiences of gaining and developing knowledge and competence in clinical settings.

The information letter described that the discussion would take place during working hours when the shifts overlapped. All managers approved the study, and they also provided oral information to the midwives attending a regular labour ward meeting. The managers of the hospital clinics were provided contact details of midwives who were interested to participate. Twenty midwives from the four hospitals expressed interest to participate in the study and were sent written information about the study prior to the focus groups.

In the information letter, they were informed about the purpose of the focus groups. It was also clarified that participation was voluntary and if they wanted to withdraw they could do so at any time without further explanation. The midwives were guaranteed full confidentiality. The time and the location of the interviews were agreed upon.

Four focus groups were carried out with 14 participants. The number of midwives in each group varied between two and six. The professional experience of the midwives ranged from 7 months to 27 years, and the median experience was 15 years. Most of the participants had long experience, but there were a few who were newly graduated. Internal rotation was applied in the hospitals where the focus groups were conducted. All midwives participating in the focus groups rotated between the delivery ward, postpartum care and gynaecological ward. Some groups were small, which was an advantage since the researchers could focus on what was said in the discussions to ensure that the data would meet the research goals. ${ }^{22}$

\subsection{Focus groups}

The locations selected were comfortable, accessible, easy to find and acoustically amenable to audiotape recordings. ${ }^{21}$ Two researchers conducted the interviews; one acted as a moderator and the other as an observer. The moderator led the discussions, and the observer handled the technical equipment and took notes. The moderator started by posing open questions, such as: "What is knowledge in midwifery, and how do you gain knowledge?" "What is competence?" "How do you achieve competence?" More probing questions were also asked, such as "What do you think about..." "Can you explain..." or "Tell us more about that". The interviews lasted between 42 and $54 \mathrm{~min}$; the median time was $50 \mathrm{~min}$. All interviews were tape recorded and transcribed verbatim by the first and the third author.

\subsection{Data analysis}

Qualitative content analysis was used. ${ }^{23}$ The text of the interviews was read repeatedly in order to develop a deeper understanding. The analysis was guided by the aim of the 
Table 1

Examples of the content analysis.

\begin{tabular}{|c|c|c|c|c|}
\hline Meaning unit & Condensation & Code & Subcategory & Category \\
\hline $\begin{array}{l}\text { You can learn to act and be in the ward, } \\
\text { theoretically, but how to feel safe, } \\
\text { it comes by years }\end{array}$ & $\begin{array}{l}\text { You get experience } \\
\text { with the time }\end{array}$ & Experience & $\begin{array}{l}\text { Time gives experience } \\
\text { and safety }\end{array}$ & $\begin{array}{l}\text { Feelings of professional safety } \\
\text { evolve over time }\end{array}$ \\
\hline $\begin{array}{l}\text { It is not necessary to work } 20 \text { years to } \\
\text { feel safe in the role, it depends on } \\
\text { the person }\end{array}$ & $\begin{array}{l}\text { To feel safe is a } \\
\text { matter of personal } \\
\text { qualities }\end{array}$ & Personal qualities & $\begin{array}{l}\text { Personal qualities could } \\
\text { make you safe }\end{array}$ & $\begin{array}{l}\text { Personal qualities affect } \\
\text { professional development }\end{array}$ \\
\hline $\begin{array}{l}\text { Now it exists evidence and research on } \\
\text { things we do, we didn't get the } \\
\text { knowledge that way before, it was } \\
\text { only from mouth to mouth }\end{array}$ & $\begin{array}{l}\text { Evidenced based } \\
\text { research has empowered } \\
\text { knowledge }\end{array}$ & $\begin{array}{l}\text { Empowered } \\
\text { knowledge }\end{array}$ & Research & $\begin{array}{l}\text { Ways to expand knowledge } \\
\text { and competence }\end{array}$ \\
\hline $\begin{array}{l}\text { Actually, everybody has to be competent, } \\
\text { when we are supposed to work everywhere }\end{array}$ & $\begin{array}{l}\text { It demands competence } \\
\text { to be wide }\end{array}$ & $\begin{array}{l}\text { Demands of } \\
\text { competence }\end{array}$ & Competence is demanding & $\begin{array}{l}\text { Competence as developing } \\
\text { and demanding }\end{array}$ \\
\hline
\end{tabular}

study,whereby meaning units were identified. These are words or sentences that contain aspects related to each other through their content and context. When the meaning units were identified and condensed, they were labelled with codes. ${ }^{24}$ These codes were then sorted into subcategories based on how they were related. In the next step, the subcategories were labelled (Table 1). The subcategories were sorted into a number of categories. Categorisation is a system of classification that organises groups into meaningful clusters. ${ }^{25}$ To ensure credibility of the data, the authors followed the steps in the analysis process jointly and individually. The coding and condensation were discussed jointly. The interpretation of the final categories and subcategories were discussed until consensus was reached and were also subjected to peer discussions in seminars with other researchers.

\subsection{Ethics}

The study was conducted in accordance with the Helsinki declaration, and participation was voluntary. In this study, practice policy was followed; therefore, no approval from an ethical board was necessary, as employees in the health services were involved. This is in accordance with the Swedish Central Ethical review board, regulation $\mathrm{nr}$ (2003:460). At the time of the discussions the presence of the participants was a confirmation of their consent and interest to participate. They were informed that the interviews were audio recorded, and the transcribed data were coded. Further, information was given that only the researchers had access to the data, and the findings would be published without identifiable information on the participants. The categories are exemplified by quotes in the findings section.

\section{Findings}

The analysis resulted in the following four categories (Table 2):

- Feelings of professional safety evolve over time

- Personal qualities affect professional development

- Ways to expand knowledge and competence

- Competence as developing and demanding

\subsection{Feelings of competence evolve over time}

The informants claimed that to be professional in midwifery and to reach a sense of being grounded and secure in the professional life takes years of experience to achieve.

You have learned to act as a midwife, theoretically, but feelings of safety come with the years (FG 3 ).
Feelings of safety and security in the professional role were considered important, and this was a prerequisite to mediating a feeling of safety to the women and the families they meet. Midwives felt safe in their professional role and there was a link between the amount of hands-on intrapartum experience and increasing confidence that is, assisting many births made midwives feel confident.

The midwives emphasised that professional experience creates safety. Most of the midwives believed that competence is a learning process achieved through experience over time. They believed that the training and education itself did not necessarily lead to competence; rather, hands-on skills should be learned and developed during midwifery education.

You learn all the time, and you don't get the competence in school. It comes with time (FG 4).

The result showed that it was essential that the knowledge acquired during the training must be translated into practice bridging the gap between theory and clinical practice.

The relation between practical training and competence was obvious, according to most participants. Competence was to have manual skills, to know how to handle issues relating to labour and birth.

Table 2

Examples of the categories and subcategories.

\begin{tabular}{|c|c|}
\hline Categories & Subcategories \\
\hline $\begin{array}{l}\text { Feelings of professional } \\
\text { safety evolve over time }\end{array}$ & $\begin{array}{l}\text { Time gives experience } \\
\text { Competence grows with time } \\
\text { Knowledge and competence depending on } \\
\text { practices } \\
\text { Intuition } \\
\text { Education is the start }\end{array}$ \\
\hline $\begin{array}{l}\text { Personal qualities affects } \\
\text { professional development }\end{array}$ & $\begin{array}{l}\text { Personal qualities could make you feel safe } \\
\text { To be interested matters } \\
\text { Personal experiences } \\
\text { Communication } \\
\text { Confidence }\end{array}$ \\
\hline $\begin{array}{l}\text { Ways to expand knowledge } \\
\text { and competence }\end{array}$ & $\begin{array}{l}\text { Research } \\
\text { Education } \\
\text { Internal rotation } \\
\text { Collegial learning } \\
\text { Students }\end{array}$ \\
\hline $\begin{array}{l}\text { Competence as developing } \\
\text { and demanding }\end{array}$ & $\begin{array}{l}\text { Competence is demanding } \\
\text { To be new is difficult } \\
\text { Knowledge and competence is complex } \\
\text { Broad competence can increase competence } \\
\text { Rotation }\end{array}$ \\
\hline
\end{tabular}


Competence is what you learn during the journey when you work (FG 3).

There were few opinions expressed about educational knowledge, and education was seen as a base for continued learning not an end in itself. Knowledge starts with education, and must be built on, midwives said:

For me, knowledge is the things you can read, midwifery education, what I should learn (FG 1).

Still, education was not described as a guarantee of competence. Another midwife stated that newly qualified midwives do not have competence, they may have the formal competence, but they don't have the real competence because they have not started to practise midwifery and lack the experience.

Another important factor essential for learning and developing competence was the feeling of intuition. It was made clear in several groups that intuition is developed through midwifery experience. The recognition of certain signs and events help to understand how to meet the needs of and care for women in labour. The experience of being with a woman in labour endows midwives with ways of caring and performing the necessary actions. The midwives felt safe by trusting their intuition and experience. One midwife stated:

It is important for me to use my intuition. It is my tool that comes with my experience (FG 3).

\subsection{Personal qualities affect professional development}

The discussions in the focus groups made it clear that competence and confidence are also related to personal qualities and capacities. One midwife talked about confidence in a birthing situation and meant that such confidence is visible; it could be seen when a midwife radiated self-confidence. Another midwife stated that having the knowledge about what to do made her feel safe in the professional role, and this created confidence:

Knowledge is to know, to feel safe in the role (FG 1). Other personal qualities such as humility were talked about as important. This was exemplified as an awareness of the necessity to discuss situations with colleagues when it was not quite clear what the course of action would be, and together reach a decision on how to precede. To be competent and professional was to take responsibility for own knowledge and to know one's own professional limitations.

You have to show your own weakness. I may have the knowledge, but I need the help from colleagues (FG 2). To develop a professional interest in certain areas of the work was considered a means to improve competence:

Of course, you can be good at what you are interested in, and develop that to be better in a specific area (FG 4).

It was not considered necessary to work for 20 years to feel safe and confident in the professional role. Personal qualities like selfefficacy also mattered. Some of the midwives looked upon personal life experiences and knowledge as tools to develop competence. One midwife mentioned communication skills as an area of competence. These responses differed among the midwives.

And we might think that we provide the same information, but one person might mediate it in a different way. Also, it may well be the same thing we (intend to) say, but depending on different skills to communicate, we may not express it in the same way. It has, of course, to do with communication (FG 2).

\subsection{Ways to expand knowledge and competence}

There were several ways described by the informants as to how to develop professionally. One way to be more informed and inspired was to attend courses presenting new knowledge. Sharing competence with other midwives in a pedagogical way was a method for expanding knowledge and educating each other about topics of interest. This was described as collegial learning or training and midwives' colleagues had a responsibility to spread new knowledge after taking part in courses or conferences.

If you have a skill...you can teach so that others understand, and make it practical (FG 2).

The team was important, and midwives supported and complemented each other's competence. Working together with colleagues and observing how they handled the birth, supported the woman and acted in the labour room was stimulating and developed knowledge.

It is good to be with others in the (labour) room, to watch and get new ideas of how to do things (FG 3 ).

Being a supervisor was another way to expand knowledge, because midwifery students brought new scientific knowledge into the maternity wards. Students were said to update supervising midwives who were interested in new research studies. Supervising students was described as a mutual learning experience, " $a$ win-win situation for all". One midwife explained it thus:

Midwifery students give us new knowledge; they are so openminded and want to share what they learn with us (FG 3). One midwife highlighted the importance of evidence-based research, a source of knowledge now easily accessible on the Internet.

Nowadays evidence and research on things we do exists online and is easily accessible. We didn't get the knowledge that way before; it was only from mouth to mouth (FG 2).

\subsection{Competence as developing and demanding}

It was a general opinion that midwifery competence covered many areas. Some midwives expressed this in a satisfying way and appreciated the flexibility in the work. Broad competence was valued, though it implied shifting tasks. Still, these were considered the terms to be able to fulfil the duties as a midwife. One midwife described working tasks during a day like this:

Yes, a lot can happen during a shift on a weekend, when we have only basic staffing. I assist a birth, and then I care for mothers and new-borns in the postpartum ward. After that I help with a child coming for a visit to the paediatrician. A gynaecological patient needs attention, and then an ambulance is on the way at the end of a day. Sometimes it feels too much to keep up with during a day. Of course it can feel fragmented, having such broad competence, but if you work as a midwife, you want to be part of it (FG 2).

Another result from the focus groups was the concern expressed about the internal rotation (e.g. labour ward, postpartum care and gynaecological ward) practised at all hospitals where the focus groups were held. This was a much-debated topic among the midwives. Some midwives were convinced that this was beneficial and broadened their competence. Others claimed that the rotation restricted their focus on attending births and made them feel split between different assignments. Some of the midwives found it more valuable to focus on certain areas, and there were severaldoubts about their capability to be fully competent to satisfactorily cover all the required areas. The need for a broad 
competence could be experienced as demanding and burdensome when the midwives were rotated between different wards. It took a lot of energy to be up-to-date in all the guidelines because of the internal rotation.

Actually, everybody has to be competent, if we need to work everywhere (FG 2).

Several midwives preferred to focus on intrapartum care rather than gynaecological nursing. They were not satisfied with the mix of duties. The alternation between wards made them feel insecure and not confident about what should be done.

I would feel more satisfied if I didn't rotate (FG 1).

Finally, when discussing internal rotation, midwives reflected on the hands-on skills, that is the ability to perform the appropriate manoeuvres, and they found it troublesome that the rotation in their work decreased the number of births they attended. The midwives described the link between amount of hands-on intrapartum experiences and increasing confidence. Most of the midwives disliked internal rotation. They wanted to deepen their competence in some certain area, which developed confidence and made them feel safe. It was experienced as demanding and burdensome to be forced into situations where new knowledge and skills had to be learned.

We speak about the competence of assisting at births. You are afraid of losing it (FG 1).

In all focus groups the problems of poor staffing were discussed and the midwives were convinced that it affected their confidence. It was perceived to be difficult to provide sufficient care and the informants described an ethical stress, that is, they knew what they were supposed to do, but did not work as they were expected to do, due to a shortage of staff. The shortage of staff especially affected the new midwives.

\section{Discussion}

The main findings in this study were that participants reported that the professional confidence of midwives develops over time. There were several ways to develop knowledge. Personal qualities were of importance and competence was considered as both developing and demanding.

The results of this study indicate that achieving competence is a time-consuming process. Dewey and Small ${ }^{26}$ declared many years ago that it takes time to become competent. They meant that learning to be competent is a process, which shapes the individual's power and is continually forming habits, ideas, and arousing feelings and emotions. It includes a psychological and a sociological process, and the learning experience is important. ${ }^{26}$ Confidence was of real importance according to the midwives, which is in line with Crooks et al., ${ }^{27}$ who described it as one of the most important factors for gaining knowledge and competence. They further described confidence as an internal feeling of selfassurance and comfort. Confidence was also related to Bandura's self-efficacy theory. ${ }^{16}$ The midwives described it in terms of "it is not necessary to work 20 years to feel safe and confident in the role". They thought that different personal life events and experiences could contribute to strengthening the feeling of self-efficacy, which could lead to increased confidence. Fullerton et al. ${ }^{28}$ describe competence as necessary and underlying knowledge. It incorporates a capacity for critical thinking, ethics and values. Competence evolves over time, and Berggren ${ }^{17}$ reported (in line with this study) that midwives believed that competence grows with experience.

As shown in the results, personal internal qualities affect professional development and this illustrates the importance of the inner capacity to achieve knowledge and competence. Sarvimäki ${ }^{29}$ claimed that the development of internal characteristics requires cognitive actions, and an open mind. Further, the capability to absorb all impressions enhances the learning process. Personal internal qualities are also related to Bandura's selfefficacy theory. Other internal capacities were recognised in the results, such as being able to communicate and meet a woman in labour, quickly connect with her, and make her feel safe. This is in line with studies showing that communication, having the right attitude and the need for the midwife to be motivated, caring and kind, are of crucial importance. ${ }^{30-33}$

The midwives considered the quality of being humble as a personal resource. This is a characteristic that is nourished in a positive clinical environment in the labour ward. Chapman and Giles $^{34}$ state that the learning is more effective if the environment is warm, supporting and enjoyable, which gives a feeling of safety. An enabling and encouraging atmosphere creates possibilities for midwives to reflect on actions or events, and critically look upon the state of midwifery care, supporting each other for professional development. Bedwell et al. ${ }^{18}$ stressed the importance of a supportive workplace, which has influence on the individual midwife. There was consensus in the focus groups that both internal factors, like self-efficacy and external factors, like a supportive workplace, contributed to the development of competence and confidence. Some midwives in our study were clear about the workplace influence, and indicated that if they did not feel supported, this could lead to feelings of uncertainty, fear, stagnation and feelings of being neglected and unimportant. The midwives described ways to develop knowledge and competence, and gave different examples on how to develop professionally, not only through clinical practice. Courses, conferences, collegial learning and supervising students were mentioned as competence-broadening activities. This is in accordance with the study by Fullerton et al., ${ }^{28}$ who stated that it is clearly important for midwives to improve their confidence in several ways. Midwives, as well as midwifery students, need training and education to develop in their profession. ${ }^{35}$ To have early exposure to hands-on experience in clinical midwifery practice and woman-centred care provides students the opportunity to link theory into practice. ${ }^{36,37}$ In the discussions participants made clear that being a good midwife and developing professionalism meant training, but also taking part in evidence-based research. The midwives who mentioned that students increase the scientific knowledge in the labour wards were aware of the importance of combining theory and practice. Supervising students was considered to be a "win-win" situation; they paid attention to the important factors for student development. In the relationship among student midwives, there is an exchange of knowledge that is mutually beneficial. In a midwifery context there are studies that acknowledge the importance of theoretical thinking and practical doing and the problem of linking it together. ${ }^{38}$ Competence was described as both developing and demanding. External factors that affected the midwives were the organisation at the four hospitals that used rotation duty. This is partly reflected by the statements from those midwives having difficulties understanding the demands from the organisation, they did not feel supported in the profession and they did not understand the benefit with rotation duty. Some midwives described feelings of resignation, since poor staffing made them unable to give proper care. The internal rotation was considered demanding, since they had to have updated knowledge in all areas. That is an important finding, considering that many midwives have left the profession in recent years. $^{39,40}$ Midwives need to be able to develop meaningful relationships with childbearing women. A midwife stays in the profession because of feeling supported and valued by colleagues, managers and women. Midwives need adequate resources and 
control and flexibility within their work. ${ }^{41,42}$ However, despite the demands, the informants were positive about their profession and there were several joyful statements given about their work.

\subsection{Methodological considerations}

One of the limitations of this study was the group with only two participants. However, their discussion contributed a great deal and was included in the data. More midwives were supposed to participate but due to a heavy workload that particular day they could not attend. It can also be advantageous with a small group, where the participants had the opportunity to express themselves and to receive attention. ${ }^{22}$ Another reason for the low participation rate might be that it was considered to be difficult to discuss the development of competence in a group of colleagues. It is a known fact that some people are not comfortable expressing their views in a group, ${ }^{21}$ but in these groups of midwives it was quite clear that the subject of the discussion was deemed important. Most of the participants had a long working experience, and there were a few newly graduated midwives. The mix of participants was beneficial and the group dynamic was not affected negatively by the varied extent of professional experience. However, the decision to use focus groups for data collection proved accurate and effective, with all midwives taking an active part in the discussions. The researchers are midwives with long experiences of intra-partum care, and careful attention was paid throughout the focus groups and analyses to the pre-understanding that inevitably will influence the midwives discussion of knowledge and competence. Still, it was found that the pre-understanding made it possible to understand the context described. Creswell ${ }^{43}$ described that the researcher filters the data through a personal lens, and one cannot escape the personal interpretation brought to qualitative data analysis. It is not possible to analyse this without imposing one's own interpretations. Patton ${ }^{44}$ describes the interpretation as: "the whole is understood as a complex system that is greater than the sum of its parts". Trustworthiness is one important aspect in qualitative research, which includes how to judge the similarities and differences between categories. Dependability is one way to ensure this. In this study the same person conducted the interviews in the same week. The focus groups discussions were conducted in Swedish and parts of the transcribed text were translated to English. A special focus was on the citations and to maintain the integrity of the data. The researchers are experienced midwives and familiar with qualitative methods, which ensures the trustworthiness of the translation. Performing the steps in the analysis process, individually and jointly ensured credibility and conformability. To draw conclusions about what constitutes the truth and achieving credibility, triangulation could be useful. ${ }^{21}$ These steps are conducted to achieve transferability. The strength of this study is that the midwives participated with interest and enthusiasm, and they entered the discussion with engagement, and gave rich descriptions of the culture. They all had something to report and made useful contributions to elucidate the facts.

\section{Conclusion}

External factors that contribute to knowledge and competence are the ability to practise hands-on skills. Further, an environment with an organisation characterised by a "willingness to learn" that offers a warm, supportive and non-threatening environment, is also a strong contributor for enhancing competence and confidence. Internal personal qualities are factors such as self-efficacy, confidence and a curiosity for learning are important for developing knowledge and competence. These internal and external factors are important, and contribute to the development of midwifery. A maternity organisation with a clinical environment that is influenced by collegial learning, clinical support and ability for midwives to develop in the profession is desirable. Midwives working within an organisation should be supported to develop their professional role in order to become knowledgeable, competent and confident.

\section{Acknowledgements}

We are most thankful to the midwives who gave rich descriptions of their meaning of knowledge and competence. We also thank Mid Sweden University research school and Jämtland County Council for financial and peer support.

\section{References}

1. Lundgren I, Berg M. Central concepts in the midwife-woman relationship. Scand J Caring Sci 2007;21(2):220-8. http://dx.doi.org/10.1111/j.1471-6712. 2007.00460.x

2. Hildingsson I, Johansson M, Karlström A, Fenwick J. Factors associated with a positive birth experience: an exploration of Swedish women's experiences. Int J Childbirth 2013;3(3):153-64. http://dx.doi.org/10.1891/2156-5287.3.3.153.

3. Moloney S, Gair S. Empathy and spiritual care in midwifery practice: contributing to women's enhanced birth experiences. Women Birth 2015. http:// dx.doi.org/10.1016/j.wombi.2015.04.009.

4. Sharma B, Hildingsson I, Johansson E, Prakasamma M, Ramani KV, Christensson $K$. Do the pre-service education programmes for midwives in India prepare confident 'registered midwives'? A survey from India. Global Health Action 2015;8:29553. http://dx.doi.org/10.3402/gha.v8 29553.

5. ICM. In: (ICM) ICoM, editor. ICM. Essential competencies for basic midwifery practice. 2013. www.internationalmidwives.org.

6. Hermansson E, Mårtensson L. The evolution of midwifery education at the masters level: a study of Swedish midwifery education programmes after the implementation of the Bologna process. Nurse Educ Today 2012;33:866-72. http://dx.doi.org/10.1016/j.nedt.2012.09.015.

7. The Swedish National Board of Health and Welfare. Description of competences for registered midwife. [Kompetensbeskrivning för legitimerad barnmorska]. Stockholm: The National Board of Health and Welfare; 2006 . www. socialstyrelsen.se.

8. Larsson M, Aldegarmann U, Aarts C. Professional role and identity in a changing society: three paradoxes in Swedish midwives' experiences. Midwifery 2009;25(4):373-81. http://dx.doi.org/10.1016/j.midw.2007.07.009.

9. Oxford dictionaries online. Confidence. 2016. Retrieved February 16, 2016 from http://www.oxforddictionaries.com/definition/english/confidence.

10. Norman M, Hyland T. The role of confidence in lifelong learning. Educ Stud 2003;29(2-3):261-72. http://dx.doi.org/10.1080/03055690303275.

11. Sewell A, George AS. Developing efficacy beliefs in the class-room. J Educ Enquiry 2000;1(2):58-71.

12. Currie SM. Aspects of the preparation of student midwives for autonomous practice. Midwifery 1999;15(4):283-92. http://dx.doi.org/10.1054/midw.1999. 0187.

13. Fraser DM. Action research to improve the pre-registration midwifery curriculum. Part 3: can fitness for practice be guaranteed? The challenge of designing and implementing an effective assesment in practice scheme. Midwifery 2000;16(4):287-94. http://dx.doi.org/10.1054/midw.2000.0228.

14. Donovan P. Confidence in newly qualified midwives. $\mathrm{Br} J$ Midwifery 2008;16(8):510-4.

15. Bryar R, Sinclair M. Theory for midwifery practice. 2nd ed. Palgrave Macmillan: Chippenham and Eastbourn; 2011.

16. Bandura A. Self-efficacy in changing society. Cambridge: Cambridge University Press; 1995.

17. Berggren A-C. Hade jag inte läst de där artiklarna. ...Barnmorskors förhållningssätt till användning av forskningsresultat inom omvårdnad. [If i hadn't read those articles..." midwives attitudes to the use of reseach results in caring]. Lunds Universitet: Pedagogic Institution; 2003.

18. Bedwell C, McGowan L, Lavender T. Factors affecting midwives' confidence in intrapartum care: a phenomenological study. Midwifery 2015;31(1):170-6. http://dx.doi.org/10.1016/j.midw.2014.08.004.

19. Davis D, Foureur M, Clements V, Brodie P, Herbison P. The self reported confidence of newly graduated midwives before and after their first year of practice in Sydney, Australia. Women Birth 2012;25(3):e1-0. http://dx.doi.org/ 10.1016/j.wombi.2011.03.005.

20. Jordan R, Farley CL. The confidence to practice midwifery: preceptor influence on student self-efficacy. J Midwifery Womens Health 2008;53(5):413-20. http:// dx.doi.org/10.1016/j.mvh.2008.05.001.

21. Polit DF, Beck CT. Nursing research: generating and assessing evidence for nursing practice. Lippincott Williams \& Wilkins; 2008.

22. Morgan DL. Reconsidering the role of interaction in analyzing and reporting focus groups. Qual Health Res 2010;20(5):718-22. http://dx.doi.org/10.1177/ 1049732310364627. 
23. Graneheim UH, Lundman B. Qualitative content analysis in nursing research: concepts, procedures and measures to achieve trustworthiness. Nurse Educ Today 2004;24:105-12. http://dx.doi.org/10.1016/j.nedt.2003.10.001.

24. Elo S, Kyngäs $\mathrm{H}$. The qualitative content analysis process. J Adv Nurs 2008;62(1):107-15. http://dx.doi.org/10.1111/j.1365-2648.2007.04569.x.

25. Hsieh HF, Shannon SE. Three approaches to qualitative content analysis. Qual Health Res 2005;15:1277-88. http://dx.doi.org/10.1177/1049732305276687.

26. Dewey J, Small AW. My pedagogic creed. EL Kellogg \& Company; 1897.

27. Crooks D, Carpio B, Brown B, Black M, O'Mara L, Noesgaard C. Development of professional confidence by post diploma baccalaureate nursing students. Nurse Educ Pract 2005;5:360-7. http://dx.doi.org/10.1016/j.nepr.2005.05.007.

28. Fullerton JT, Thompson JB, Johnson P. Competency-based education: the essential basis of pre-service education for the professional midwifery workforce. Midwifery 2013;29:1129-36. http://dx.doi.org/10.1016/j.midw.2013.07.006.

29. Sarvimäki A. Kunskapsteoretiska och ontologiska perspektiv på erfarenhetsbaserad kunskap [Epistemological and ontological perspective on experiencebased knowledge]. In: Östlinder G, Norberg A, Pilhammar Andersson E, Öhlen J, editors. Erfarenhetsbaserad kunskap- vad är det och hur värderar vi den?Evidence-based knowledge- what is it and how do we value it?Stockholm: Svensk sjuksköterskeförening (Swedish nurse association); 2006.

30. Butler MM, Fraser DM, Murphy RJ. What are the essential competencies required of a midwife at the point of registration? Midwifery 2008;24(3):260-9. http:// dx.doi.org/10.1016/i.midw.2006.10.010.

31. Byrom S, Downe S. 'She sort of shines': midwives' accounts of 'good' midwifery and 'good' leadership. Midwifery 2010;26(1):126-37. http://dx.doi.org/ 10.1016/j.midw.2008.01.011.

32. Halldorsdottir S, Karlsdottir SI. The primacy of the good midwife in midwifery services: an evolving theory of professionalism in midwifery. Scand J Caring Sci 2011;25(4):806-17. http://dx.doi.org/10.1111/j.1471-6712.2011.00886.x.

33. Thelin IL, Lundgren I, Hermansson E. Midwives' lived experience of caring during childbirth - a phenomenological study. Sex Reprod Healthc 2014;5(3):113-8. http://dx.doi.org/10.1016/j.srhc.2014.06.008.
34. Chapman L, Giles D. Using appreciative inquiry to explore the professional practice of a midwife lecturer. Stud Contin Educ 2009;31(3):297-305. http:/ dx.doi.org/10.1080/01580370903271487.

35. Abedian K, Charati JY, Samadaee K, Shahhosseini Z. A cross-sectional study of midwives' perspectives towards their professional educational needs. Mater Sociomed 2014;26(3):182-5. http://dx.doi.org/10.5455/msm.2014.26.182-185.

36. Sidebotham M, Fenwick J, Carter A, Gamble J. Using the five senses of success framework to understand the experiences of midwifery students enroled in an undergraduate degree program. Midwifery 2015;31(1):201-7. http:/ dx.doi.org/10.1016/j.midw.2014.08.007.

37. McKenna LG, Wray N, McCall L. Exploring continuous clinical placement for undergraduate students. Adv Health Sci Educ Theory Pract 2009;14(3):327-35. http://dx.doi.org/10.1007/s10459-008-9116-4.

38. Rolloff M. A constructivist model for teaching evidence-based practice. Nurs Educ Perspect 2010;31(5):290-3. http://dx.doi.org/10.1043/1536-5026-31.5. 290.

39. Hildingsson I, Westlund K, Wiklund I. Burnout in Swedish midwives. Sex Reprod Healthc 2013;4(3):87-91. http://dx.doi.org/10.1016/j.srhc.2013.07.001.

40. Mckenna H, Keeney S, Hasson F. Health care managers' perspectives on new nursing and midwifery roles: perceived impact on patient care and cost effectiveness. J Nurs Manag 2009;17(5):627-35. http://dx.doi.org/10.1111/ j.1365-2834.2008.00948.x.

41. Sullivan K, Lock L, Homer CS. Factors that contribute to midwives staying in midwifery: a study in one area health service in New South Wales, Australia. Midwifery 2011;27(3):331-5. http://dx.doi.org/10.1016/j.midw.2011.01.007.

42. Hunter B, Warren L. Midwives' experiences of workplace resilience. Midwifery 2014;30(8):926-34. http://dx.doi.org/10.1016/j.midw.2014.03.010.

43. Creswell JW. Research design. Qualitative, quantitative, and mixed methods approaches. 2nd ed. Thousand Oaks: Sage Publications, Inc.; 2003.

44. Patton MQ. Qualitative research E evaluation methods. 3rd ed. London: Sage Publications, Inc.; 2002. 